\title{
The Durability of Modern Book Papers.'
}

THE rôle of a Cassandra has always been an unpopular one, and unless the prophet of evil can hope that words of warning may result in something being done to avert the threatened calamity it is also a very painful role. My business at the present time is as briefly as possible to tell you that it is in vain for you to extend your libraries and to make provision for the accessions of many years to come-and for this melancholy reason, that, as generation follows generation, you will find sufficient empty space on your shelves for the new books of the day, in consequence of those of the past day having crumbled to dust. This is no freak of imagination, or result of hysterical fears, but is sadly confirmed by the chemical analysis of distinguished analysts. It is now nearly fifteen years since my attention was first drawn to the subject of the durability of modern book papers; and, as Librarian of the Leeds Library, I made certain simple experiments and observations which convinced me that many of the books on our shelves there, even if left untouched, would not outlast the present generation of readers, and I approached some of the leading publishers on the question, but with no useful result.

$\mathrm{My}$ interest in the matter has been revived recently by observing the rapid disintegration that is taking place among modern scientific books, among which my official work chiefly lies. Anyone who is familiar with our earliest literature knows that the paper of the early printers is, so far as mere durability is concerned, equal to the best parchment ; and, indeed, under certain circumstances is more likely to endure than vellum. I know nothing of chemistry, and cannot discuss the subject in scientific terms; but, through the kindness of Mr. Wheatley, I have been introduced to Mr. J. F. Cross, a distinguished

\footnotetext{
'Read before the Trentietb Annual Meeting of the Library Araciation, London, October, 1897.
} 
analytical chemist, who has made a special study of this question, and some short time ago delivered a series of lectures in these rooms, in the course of which he drew special attention to the durability of papers. He has given me permission to freely quote from his lectures, and from a work on Cellulose, ${ }^{1}$ written by himself and his partner, Mr. Bevan. He has also kindly supplied me with some original notes, which I propose to lay before you.

The majority of the printing papers used in this country fall into two classes ;-

(r) The staple fibre is that obtained from Esparto.

(2) The chief fibrous component is the mbchanical wood pulp or ground wood.

Between these extremes there are numbers of intermediate types of composition.

Both classes are freely "qualified " by admixtures of loading matter, chiefly china clay.

It is not to be assumed that the use of these materials is a question of cheapness only. The paper maker would have a good deal to say as to the advantageous effects of these materials on the paper. One thing, however, may be safely said: papers are bought and sold chiefly on external characteristics, e.g., colour, finish, or surface, "bulk," and tearing strength, taken together with the price.

The objections to the above materials are chiefly those based upon their chemical characteristics, which result in inferiority in resistance.

Without going into scientific details, I will briefly describe what Mr. Cross has indicated as a standard book paper.

(a) (When price is of purely secondary moment.) Paper composed only of cotton and flax (or linen) fibres-mineral matter not exceeding 5 per cent.

(b) (Where the limit of say $3 \mathrm{~d}$. per $\mathrm{lb}$. has to be respected.) Papers containing chemical wood pulps up to 75 per cent., and rag fibres 25 per cent. Total mineral matter not exceeding 7 per cent.

It is unnecessary for us as librarians to inquire too curiously into the scientific side of the question; and bearing in mind that few of us are fitted by scientific training to deal with the question in this way, I have obtained simple tests and formula which will enable you to test for yourselves the paper of books

' Cantor Lectures, 1897. Calmaser, by Cross and Bevan, 1895. 
submitted to you on approval. It is by no means the cheapest papers that are the least durable, some of the most superfine, handsomest and best-looking papers are those which in all probability will perish soonest. Indeed, it would seem that all that has been done of late years to improve the appearance and finish of papers tends to the earlier destruction of these papers. If we examine a good book of the fifteenth, sixteenth, and seventeenth centuries, we find that the paper is rougher of surface and of a creamy tint. Modern paper-makers have striven to supply us with a paper purely white, and of highly finished surface, and both the bleaching and sizing very seriously affect the life of the paper. No one who has carefully considered the subject or who has compared old with new, will hesitate to say that the old creamy tinted unsized paper of from roo to 400 years ago is far superior in appearance and everything else to the modern, dazzling white, highly polished paper, and we must, quite apart from the important question of the material of the paper, convince first publishers, and then manufacturers, that we prefer the old style of paper to the new. The chemicals used for bleaching and for glazing or sizing, from the moment they are applied, set up a disintegrating process of the paper, and all that the paper needs in order to become dust is plenty of air and light, and the process is none the worse for a little damp. It is impossible to exaggerate the importance of this question when we realise that some of the most important history-making documents of the day, including The Times and other newspapers, our Blue Books, and many of our Government Reports, are printed on the worst possible paper from the point of view of durability. A distinguished German chemist has given much attention to this subject, has found that our British Stationery Office is almost the worst offender in this respect, and it is probable our noble series of British Blue Books will have disappeared long before Macaulay's Now Zealander will have have had a chance of perusing them.

I take it that librarians more than any others are bound to deal with this question seriously. It may be said that authors, editors, and publishers, have done their work when the books they are responsible for have been duly published and distributed, but it is the duty of the librarian to preserve these books, to catalogue them, and to index them in such a fashion that they shall be instantly available, not only for the present generation, but for the generations to come, and if he has to 
spend his time in shelving, cataloguing and indexing books that shall before long have been crumbled to dust, surely his labour is in vain. Therefore I have thought it well to bring the matter before the Library Association, not merely to discuss it in an abstract fashion, but I hope with the result of getting you to resolve upon definite action which shall do something to remedy the evil. I lately addressed the following letter to some of our principal publishers, and from most of them have received courteous replies, in most cases showing that they had given the question some thought, and in all, agreeing that it was bne of serious importance.

$$
\begin{aligned}
& \text { “The Library Association, } \\
& \text { “ 20, Hanover Square, London, W. }
\end{aligned}
$$

“ Dear Sir,-Will you kindly let me know whether you would be willing to entertain proposals for the printing of small editions of your more important future works on special paper for the use of libraries. You are, of course, aware that some of the paper now used for books is of such a nature that in all probability it will perish within a comparatively short period, and that there is good reason for believing that not many years hence many of the books of this generation will have ceased to exist unless reprinted.

"This is not merely a question of cheap versus dear papers, for some comparatively costly and fine-looking papers are even more perishable than certain cheaper papers. I should be greatly obliged if you would favour me with your views on the subject.

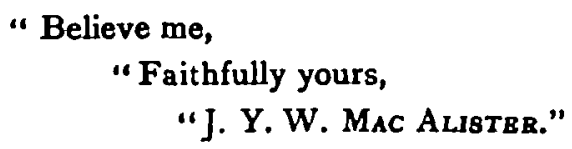

I will read a few extracts from the replies.

\section{Abstracts From Publishers' Letters.}

Massrs. Walter Scott, Limited.- "We are afraid we do not publish many works of such importance as to make it desirable that they should be produced in such a form as to impart to them a sort of material immortality. But is it not the assumption that books are placed in a library to be used, and being comparativaly fragile, however made, that they will in more or less time wear away? And if a book is important to a succeeding generation, 
that generation is sure to reprint it. The important book will always take care of itself."

J. B. Lippincott \& Co.- "It would certainly be a good thing to have a certain number of copies of standard works printed on a more durable paper, but whether it would be possible to persuade publishers to print and librarians to buy such special copies is a matter about which we have considerable doubt."

Messrs. G. Bell \&. Sons.- "We can only say that we fully realise the unsatisfactory character of much of the paper used in printing books, and that we should be very glad to support any practicable scheme for obviating the inconveniences to which this state of things is likely to give rise.

"In the case of most of our expensive publications we already meet the difficulty by printing small editions on Japanese or handmade paper, but it is impossible to do this with every book, and the only suggestion we can make is that paper-makers should be induced to manufacture a good paper at a moderate price in order that the first edition, at least, of cheap publications should be printed on durable material. We feel very doubtful whether any of the machine-made papers at present in the market have the requisite qualifications in respect to both price and material, and it is almost impossible for anyone but the makers to say what any cheap paper is now made of."

Digby, Long \&. Co.-." . . . . are disposed to think with you that there is a tendency now-a-days to print books on a paper of less durability than formerly, and any proposal you may have to make as regards the paper to be used for any important future works we may issue, we shall be pleased to entertain it."

William Heinomann.- "I am éntirely in sympathy with your proposal, and shall be only too delighted in any way to assist in the matter if it is at all possible. The trouble is that paper with a sufficient finish to 'take' process engravings cannot, as far as I know, be made of material that is likely to be lasting. In all other cases I have taken particular care to print my books wherever I could on paper that was likely to last.

"It would be quite possible to print of certain books a special edition for the members of the Library Association, and the question then would be whether a sufficient number of members would be willing to bear collectively the extra expense."

Sampson Low, Marston \&. Co., Linnited.- "We should be perfectly willing to entertain a proposal for printing small editions of our more important publications on special paper for the use 
of libraries, if we could be assured that the libraries would buy copies and would be willing to pay a higher price.

"We are, of course, aware that the vast majority of books printed to-day will soon perish."

Swan Sonnenscluein \& Co., Limited.- "If the libraries were to combine and order before publication a sufficient number of copies of a book, we should be pleased to use a more enduring paper, charging a small extra price for the same. Could not the Library Association undertake this function? If so, we think publishers would readily advise the Library Association as to new books before they were machined. Probably a hand-made paper would be best, and the extra cost per book would be trifling. If the Library Association could order say roo copies, this number would be worth machining, provided it could be machined at the same tiwne as the ordinary adition."

Thomas Nelson \& Sons. - "We should be glad to consider any application for a small edition of any of our books on special paper for libraries, but without such application we do not think that we can carry out your suggestion."

Edward Arnold.- "We are much obliged for your letter, but we fear it would not be practicable to print small editions in the way you suggest. We take great precautions with our paper already, and will bear your letter in mind in our future arrangements."

Chatto \& Windus.-_" We do not think that the demand would be sufficiently great to warrant printing special editions of ordinary books for the use of libraries. The need for special preparation would in most cases considerably enhance the cost of production, and in the case of illustrated books the price would become prohibitive if special small editions were prepared. Moreover, stocks of the finer papers are, as a rule, not kept by any house, and could not be, now that books are so many, and vary so in both size and thickness.

"However, we try to use fairly good paper for all our books, and have it manufactured from lasting material, so that we hope. it may last for much more than the hundred years you name as a limit.

"If by the 'comparatively costly and fine-looking paper ' you speak of you mean the 'coated' paper used for balf-tone process blocks, we acknowledge that the surface may in time be disintegrated by damp and the chemical action of gas, atmosphere, \&c., but this seems unavoidable while the public instst upon 
books being produced at a price which does not admit of the oldfashioned wood engravings being used, even if illustration blocks could now be produced by the old methods in sufficient numbers to supply the needs of the reading public, which, of course, they could not be without the use of the new processes."

William Clowes \& Sons, Limited.- " For such books as we do bring out (chiefly military drill books, \&c.), it would not be worth while printing on two papers. We may add that we are very careful in selecting the papers for these little works."

Gay \& Bird._- "We should be pleased to entertain the proposal contained therein."

A. \&. C. Black.- "We should be quite willing to print a small edition of our more important works on special paper for the use of libraries, provided that a suitable business arrangement was arrived at between us."

Frederick Wame \& Co._- We are willing to entertain any proposal in connection with the subject you mention, but it would be impossible for us, without knowledge of the same, to say whether such would be practicable; as small numbers of books cannot be specially printed with ease, except at exceptional cost."

Longmans, Green \& Co.—"We regret to say that we do not think your suggestion of a small edition being printed on special paper for the use of libraries is a very practical one. It seems doubtful whether a sufficient number of libraries would undertake to purchase a definite number of copies of all books so treated, and also whether they would be willing to pay an enhanced price owing to the book being printed on superior paper. If, however, you have any information as to the materials in paper which, by experience, have been proved to be permanent or otherwise, we should have much pleasure in giving our best attention to the matter."

Seeley \& Co., Limited.- "We should be happy to fall in with any arrangement of the kind mentioned in your letter of the $4^{\text {th }}$ inst. that the libraries might deem needful, if they would be willing to support it."

J. \& A. Churchill._" . . . Our attention has for some time been directed to the subject. So far, we have not noticed any deterioration in the books which we have printed. Hence we do not at present think that it is necessary for us to contemplate the throwing off of a small edition on specially-made paper." 
$J . M$. Dont \& Co.-."We endeavour always to use the best paper we can for the printing of our books, selecting that which is made of rags and grass, and avoiding that which contains any appreciable percentage of clay. We hope, therefore, that they will last as long as any current bocks. Of course, if we had any reason to suppose that a considerable number of libraries would support us in the endeavour to print a limited edition of works upon a very much more expensive paper, we might be disposed to do something in that way ; but, needless to say, we should hardly be prepared to buy very expensive paper for books unless we had some sort of guarantee that libraries would buy them, and them only."

Richard Bentley Eo Son.-“ . . . Will give your proposal careful consideration when future important works are arranged for. On the general question we need not say that we entirely agree with the views expressed in your letter, and in the case of an important book, such, for instance, as Lord Wolseley's Lifo of Marlborough, and Lord Roberts' Autobiography, we give effect to them by carefully selecting a paper of a better quality than those ordinarily in use. In the case of a work like Walpole's Letters, also, we hope that the hand-made paper edition, at any rate, will secure a valuable book for the needs of posterity."

7. E. C.F. Clay.-C" We can assure you that we have always before us the question of ensuring, as far as may be, the durability of the books which are printed here, and we use great care in selecting the quality of the paper which we use."

$W m$. Blackwood \&. Son.- " So far as we are concerned we think that the paper on which our books are printed, especially with the more important works, is of such a character as will bear comparison for durability, \&c., with any in the market."

Hay, Nisbet \& Co.- "The books we publish are of a nature so transitory that we do not think it necessary to comply with your suggestion, which is otherwise admirable and praiseworthy. Should we at any time publish books of a more important character, we will bear your proposals in mind."

The Clarendon Press, Oxford.- "We are thoroughly aware of the unsubstantial character of the cheap papers upon which the majority of modern books are produced, but it is one of the points of the Oxford Press that the paper of almost all our library editions is manufactured at our own mills, and is made from materials no less endurable than that of the papers of fifty years ago. We have no reason to believe that the paper upon which 
our new English Dictionary is printed, or standard works like Rashdall's History of the Uniocrsitics, will show any material signs of decay for a hundred years to come-possibly for much longer. Our papers are made now, as of old, of the best linen rag, and the only alteration is not in any dangerous ingredients, but in improved methods of manufacture. Under these circumstances we do not feel anything is to be gained here by such a course as you suggest. Doubtless our paper is not absolutely imperishable, but anything that lasts two or three hundred years is sure to be reprinted if it is worth preserving."

These replies suggest various ways of dealing with the matter : one, and a very business-like one is, that we, as an Association, should endeavour to arrange for limited editions of all the best books published, to be printed on proved durable paper, and that these copies should be purchased by libraries. I am not sure our machinery is at the present time equal to such an undertaking, although there is much to be said for a serious consideration of it. Some of the replies show that with most of the writers there are certain books which in their opinion are merely of ephemeral interest, and that it is an advantage rather than otherwise, that the paper and the books should disappear before long. But I think that no genuine librarian will agree with this view of the question, for it is not for us, in I897, to say what among the books of this year shall be deemed of great importance by our descendants 200 "years hence. Every bibliographer knows many instances of stones which the builders have rejected, which are now become the head of the corner. One plan that has occurred to me is that a short addition should be made to the Copyright Act, which should prescribe that the copies of books sent to the Copyright Libraries should be printed on paper of a certain specification. There ought to be no great difficulty in bringing this about; but after all, that would only secure that in the five great National Libraries one copy should endure. It would not protect the other libraries of the country from the rapid destruction of their treasured contents. It has been suggested that Parliament should be appealed to, and that they should prescribe a normal paper, and that no books should be printed on anything less durable; but I am afraid, in this free country, Parliament is not likely to pass any such measure; but we can do this if we will-the Library Association and the libraries connected with it may among themselves, after reasonable notice to 
the publishers, resolve that they will not admit to their shelves any books printed on paper which shall not pass certain simple tests. If such a resolution be arrived at, and loyally adhered to, I think there is little doubt that before long publishers will see that it is their interest to take pains to procure durable papers.

I will now prescribe certain simple tests by which librarians may for themselves ascertain whether the paper of the books submitted to them is composed of durable materials. If the books which do not come up to the normal standard are forthwith returned to the booksellers, we shall not have long to wait for a reform.

Mechamical wood pulp is easily detected by brushing on a little solution of an aniline salt (when it will produce a deep yellow stain), or by means of Wurster's paraphenylene diamine test papers.

Esparto. By boiling a portion (which must of course be cut away) with a solution of an aniline salt, which will produce rose-red colouration.

Microscopic tests are to be preferred as they can be applied to minute fragments of the paper; or the surface of the paper may be scraped with a knife and the detached fibres mounted and examined.

Mincral loading. For this a strip requires to be burned; the bulk and character of the ash of loaded papers at once reveals the presence of the mineral matter.

I will conclude my paper by moving the following resolution :-

"That the Council be instructed to appoint a Committee of this Association for the purpose of inquiring into the question of the durability of modern book papers, and to report as soon as possible to the Council. That the Council be further instructed to publish this report, and to take such further steps as to them seem desirable."

J. Y. W. Mac Alister. 